\title{
Tony McMichael: A Giant in the Field of Global Environmental Health
}

\author{
Jonathan A. Patz
}

Global Health Institute, Nelson Institute, and the Department of Population Health Sciences, University of Wisconsin, 1710 University Ave, Madison, WI 53726

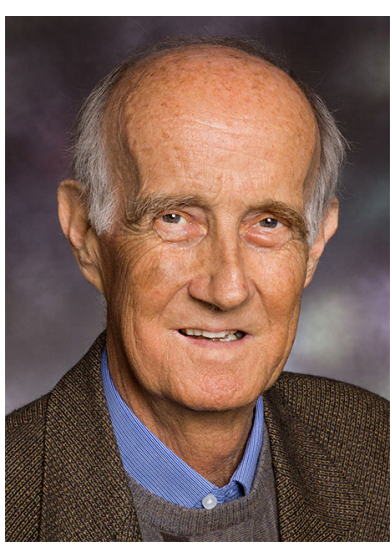

Professor Emeritus Anthony J. (Tony) McMichael, MBBS, $\mathrm{PhD}$, who passed away on September 26, 2014 was a hugely influential pioneer of global environmental health and a giant in the field of environmental epidemiology. He could be regarded along with other legendary names like Rene Dubos and Rachel Carson, who during their lives, challenged conventional assumptions and majorly advanced our understanding of the links between our environment and our health in the twentieth century; Tony Michael's discoveries and teachings are foundational for the global challenges facing us today in the twenty-first century.

McMichael's exemplary and impactful career includes some of the most important advancements to date in the field of environmental and occupational health. For

Published online: November 19, 2014

Correspondence to: Jonathan A. Patz, e-mail: patz@wisc.edu example, McMichael was the epidemiologist and co-author for the 15-year prospective study on children's IQ and lead exposure: the Port Pirie study. Tony therefore was among the first health scientists to provide robust quantitative evidence of the link between lead and brain function.

Tony McMichael's next major discovery applied to occupational health. Hazardous exposures in the workplace were common in our industrializing era, with subsequent morbidity and mortality among workers. Eventually, guidelines were made establishing "safe" levels of exposures to workers. But why did workers continue to get sick? It was Professor McMichael who first described "The Healthy Worker Effect"- whereby very sick individuals who were no longer in the workforce were left out of risk calculations. This discovery led to lowering the exposure thresholds across numerous occupational settings.

I first met Tony at the World Health Organization in 1993. At that time, WHO had just been approached by the United Nations Intergovernmental Panel on Climate Change (IPCC) to contribute a health chapter for their 2nd Assessment Report-the subject of health was missing in IPCC's first report. Naturally, it was Professor Tony McMichael who was invited to serve as "Convening Lead Author, a role for which he graciously undertook across many IPCC Assessment Reports. He also served as the lead on many other high-level international initiatives addressing global environmental health challenges.

McMichael produced over 300 peer-reviewed papers and three major books, including his 1993 book Planetary 
Overload: Global Environmental Change and Human Health that, in my mind, will forever rank alongside Debos' So Human an Animal, Aldo Leopold's A Sand County Almanac, and Carson's Silent Spring. In the book, Tony outlined the threats to health from climate change, ozone depletion, land degradation and unsustainable agriculture, biodiversity loss, and the rapid expansion of cities.

Tony McMichael's warnings from the early 1990s have become all too clear and shocking realities of today; for example, growth in greenhouse gas emissions has been the greatest in the last decade and are now twice the average rates for the period from 1970 to 2000 . And since 2008, more than half of the world's population now resides in cities, with projections of accelerating trends in urbanization. In a 2006 interview published in Environmental Health Perspectives, Tony cautioned us to cease our reductionist approach to environmental threats and to recognize the interdependence of global environmental health issues. He stated (ultimately) that, "to change the world's climate is to shake the foundations of Earth's life support systems."

McMichael grew up in Australia, studied medicine in Adelaide and also completed a $\mathrm{PhD}$ there in epidemiology in 1972. True to his nature, Tony was a global citizen serving as a faculty member in the United States (University of North Carolina), the United Kingdom (London School of Hygiene and Tropical Medicine), and of course Australia as front and back bookends to his illustrious career (University of Adelaide, CSIRO, and the Australian National University or ANU). At ANU, Professor McMichael directed the National Centre for Epidemiology and Population Health from 2001 to 2007. Tony was awarded a prestigious Australia Fellowship by the National Health and Medical Research Council in 2007, considered as "Australia's most prestigious award for excellence in the fields of health and medical research." And in 2011, McMichael earned the distinction of being appointed as an Officer of the Order of Australia and an elected member of the US National Academy of Sciences.

In their own right, Tony's family remains a tour de force as well. His wife, Judith Healy, $\mathrm{PhD}$, (who by the way, graciously donated one of her kidney's to her husband many years ago) is an Associate Professor in ANU's Research School of Pacific and Asian Studies. His younger brother, Philip McMichael, is a professor at Cornell University's Department of Development Sociology and studies global implications of agriculture and food policies, including recent land grabs for food and biofuels. One of Tony's and Judith's two daughters, Anna, is an award winning and widely recorded world-renowned violinist. Daughter Celia McMichael, $\mathrm{PhD}$, is a Lecturer at La Trobe University in Melbourne. In 2010, along with her father, she published a paper, Climate-related displacement-a climate change health topic I personally speak of as "the iceberg under the tip of the iceberg."

Finally, Tony McMichael was an incredible renaissance man. He was an encyclopedia of both biological sciences and the humanities-also reflected by the achievements of his children. He loved history, anthropology, and so much more. Tony was an accomplished pianist and truly celebrated the diversity of cultures and the human spirit.

In summary, thanks to Tony McMichael, children are smarter (from reduced lead exposure), workers are healthier (recognizing the "Healthy Worker Effect"), and the world is aware that public health is a central concern regarding today's global climate crisis. His scientific achievements and clarion call to action within his masterpiece Planetary Overload will continue to be heard around the world.

Tony was a selfless and caring professor and stellar role model to so many scientists and professionals. Through his lifetime of objective scientific inquiry, combined with efforts from so many people he has influenced, Tony has ensured that we are gaining traction in turning society away from the precipice. I will always remember Tony McMichael as a brilliant mentor and gifted teacher, a wonderful and humorous friend, and ultimately an inspiration to all. His teachings and mission will absolutely live on! 